\title{
Mapa da rede social de apoio às famílias para a promoção do desenvolvimento infantil*
}

\author{
MAP OF THE FAMILY SOCIAL SUPPORT NETWORK FOR THE PROMOTION \\ OF CHILD DEVELOPMENT
}

\author{
MAPA DE LA RED SOCIAL DE APOYO A LAS FAMILIAS PARA LA PROMOCIÓN \\ DEL DESARROLLO INFANTIL
}

\section{Ana Maria Cosvoski Alexandre ${ }^{1}$, Liliana Maria Labronici ${ }^{2}$, Mariluci Alves Maftum ${ }^{3}$ Verônica de Azevedo Mazza ${ }^{4}$}

\section{RESUMO}

Pesquisa descritiva, com abordagem qualitativa, realizada de setembro a novembro de 2009, em uma unidade de saúde com Estratégia Saúde da Família, de um município da região metropolitana de Curitiba-PR, com oito famílias, representadas por mãe, pai e avó. O objetivo foi identificar a rede social de apoio às famílias para a promoção do desenvolvimento infantil, na perspectiva das famílias. A coleta de dados ocorreu por meio da técnica de grupo focal, e os dados foram analisados segundo a análise de conteúdo. A rede social de apoio às famílias foi classificada como localizada, composta por 16 membros distribuídos entre rede informal e formal, estabelecidos por relações íntimas, com menor grau de compromisso e ocasionais. Considera-se que o entendimento por parte dos profissionais de saúde referente ao papel e importância dessa rede favorece a proposta de entrelaçamento entre os membros que contribuem para apoiar famílias na promoção do desenvolvimento infantil.

\section{DESCRITORES}

Desenvolvimento infantil

Apoio social

Família

Saúde da criança

Enfermagem pediátrica

\begin{abstract}
This descriptive, qualitative study was performed from September to November 2009, at a Family Health Strategy unit in a city in the metropolitan region of Curitiba-PR. Participants were eight families, represented by mothers, fathers and grandmothers. The study objective was to identify the family social support network for the promotion of child development, from the family's perspective. Data were collected through focal groups and subjected to content analysis. The family social support network was classified as located, consisting of 16 members distributed between the informal and formal network, established by close relationships, with a smaller level of commitment, and occasional. It is considered that the health workers' understanding regarding the role and importance of this network favors the networking proposal between members that contribute to supporting families in the promotion of child development.
\end{abstract}

\author{
DESCRIPTORS \\ Child development \\ Social support \\ Family \\ Child health \\ Pediatric nursing
}

\begin{abstract}
RESUMEN rrollo infantil.

\author{
DESCRIPTORES \\ Desarrollo infantil \\ Apoyo social \\ Familia \\ Salud del niño \\ Enfermería pediátrica
}

Investigación descriptiva, cualitativa, realizada entre septiembre y noviembre 2009, en unidade sanitaria con Estrategia Salud de la Familia de municipio de región metropolitana de Curitiba, con ocho familias representadas por madre, padre y abuelos. Se objetivó verificar la red social de apoyo a las familias para la promoción del desarrollo infantil, en la perspectiva familiar. La recolección de datos se realizó mediante técnica de grupo focal, los datos se analizaron según Análisis de Contenido. La red social de apoyo a las familias fue clasificada como localizada, compuesta por 16 miembros distribuidos entre red formal e informal, establecidos por relaciones íntimas, con menor grado de compromiso y ocasionales. Se considera que la comprensión por parte de los profesionales de salud en referencia al papel e importancia de dicha red favorece la propuesta de entrelazado entre miembros, que contribuye al apoyo de las familias en la promoción del desa-

\footnotetext{
* Extraído da dissertação "A rede social de apoio às famílias para a promoção do desenvolvimento infantil: potencial para a prática de enfermagem", Programa de Pós-Graduação em Enfermagem da Universidade Federal do Paraná, 2010. '1Enfermeira. Mestranda em Enfermagem do Programa de PósGraduação em Enfermagem da Universidade Federal do Paraná. Bolsista da Reestruturação e Expansão das Universidades Federais - Reuni. Curitiba, PR, Brasil. ana.ufpr@yahoo.com.br 2 Enfermeira. Doutora em Enfermagem. Professora Associada da Universidade Federal do Paraná. Curitiba, PR, Brasil. lililabronici@yahoo.com.br ${ }^{3}$ Enfermeira. Doutora em Enfermagem. Professora Adjunta da Universidade Federal do Paraná. Curitiba, PR, Brasil. maftum@ufpr.br ${ }^{4}$ Enfermeira. Doutora em Enfermagem. Professora Adjunta da Universidade Federal do Paraná. Curitiba, PR, Brasil. mazzas@ufpr.br
} 


\section{INTRODUÇÃO}

O cuidado à saúde da criança na atenção básica tem fundamental importância na redução da mortalidade infantil em países em desenvolvimento, porquanto os índices ainda se mostram elevados. Destarte, é no período de zero a cinco anos que a criança desenvolve grande parte do potencial físico, psicológico e emocional de toda a sua vida. Estas características conferem oportunidade ${ }^{(1)}$ para que se reconheçam os potenciais de saúde e as modificações próprias deste período da vida, ensejando que as famílias e os profissionais invistam em ações de promoção à saúde destes sujeitos.

A qualidade da atenção à saúde oferecida à criança na primeira infância influencia no sucesso escolar, no desenvolvimento de fatores de autoestima e resiliência, sendo imprescindível na continuidade da aprendizagem,

na formação das relações e da autoproteção requerida para independência econômica, no preparo do indivíduo para a vida e na convivência familiar e comunitária ${ }^{(1)}$.

Neste aspecto, as famílias têm sido reconhecidas pelos serviços de saúde na participação de atividades de proteção e ajuda, no papel de provedoras de cuidado informal e sua centralidade na função deste mesmo papel $^{(2)}$, constituindo um membro importante na rede social de apoio. Portanto, é preciso reconhecer as condições de saúde das famílias, os espaços de vida e cuidado e os recursos disponíveis que contribuem para a prática de cuidado integral à saúde da criança.

Há que se destacar que apenas a família não consegue responder a todas as necessidades de saúde das crianças, razão pela qual precisa de recursos da comunidade, das organizações sociais e do estado para minimizá-las ou solucioná-las. Devem ser ressaltados, entre estas necessidades, os serviços de saúde que podem alcançar ações integrais de cuidado $^{(3)}$. Neste sentido, a Estratégia Saúde da Família (ESF) corrobora para inclusão da família na co-responsabilidade da atenção à saúde da criança e assim obter um cuidado continuum.

Uma das principais funções da ESF é fortalecer a atenção básica através da reorganização dos serviços de saúde e, consequentemente, reformular o modelo assistencial vigente para uma proposta que tenha a família e o espaço da vida como foco das práticas ${ }^{(4)}$. As ações deste modo de organização devem centrar-se nos âmbitos do território e das famílias para que tornem possível a construção da rede de suporte do cuidado para a criança.

$\mathrm{Na}$ rede social, a ESF tem papel relevante por estabelecer ligações entre os diferentes atores que a compõem, como famílias, vizinhos e lideranças comunitárias, visto que pode estimular a inserção entre as várias iniciativas de apoio, aliando as práticas de apoio social às ações de saúde ${ }^{(3)}$.

Nesta pesquisa adotou-se o conceito de rede social proposto no estudo ${ }^{(5)}$, que a apresenta como o

(...) conjunto de seres com quem interagimos de maneira regular, com quem conversamos, com quem trocamos sinais que nos corporizam, que nos tornam reais,

ou seja, constituem uma continuidade.

Considera-se que o entendimento por parte dos profissionais de saúde referente ao papel e à importância da rede social favorece a proposta de estratégias, com entrelaçamento entre os recursos formais e informais, que contribuam para apoiar as famílias na promoção do desenvolvimento infantil. Para que isso ocorra, faz-se necessário primeiramente distinguir a rede social de apoio disponível e reconhecida pelas famílias, já que resultados de outros estudos indicam que são muitas e atuam de maneira efetiva e colaborativa no apoio à população e aos serviços ${ }^{(6)}$.

Diante de exposto, tem-se a seguinte questão norteadora: qual a rede social de apoio reconhecida pelas famílias para a promoção do desenvolvimento infantil?

\section{OBJETIVO}

Identificar a rede social de apoio às famílias para a promoção do desenvolvimento infantil, na perspectiva dos membros das famílias de crianças entre zero e cinco anos.

\section{MÉTODO}

Estudo descritivo, com abordagem qualitativa, realizado em uma Unidade de Estratégia de Saúde da Família com ESF em um município da região metropolitana de Curitiba, Paraná, no período de setembro a novembro de 2009.

A escolha do município ocorreu devido à vinculação da Universidade Federal do Paraná (UFPR) com a Secretaria de Saúde deste município, por meio de vários projetos de pesquisa e ações integradas que objetivam melhorar os serviços de saúde.

A opção pela unidade com ESF justifica-se pelas ações peculiares desenvolvidas nestes espaços, por meio de integrações diretas entre unidade de saúde e famílias, e também, por ter o maior número de crianças entre zero a cinco anos, pertencentes à sua área de abrangência.

Para a seleção das famílias, utilizou-se a divisão territorial da unidade de saúde, contemplada em três áreas, cada uma com cinco microáreas. Realizou-se um sorteio de duas ruas de cada microárea. Na sequência, identifi- 
caram-se todas as famílias que tinham crianças de zero a cinco anos que nelas residiam, tendo sido feito um sorteio das famílias, a fim de que uma família de cada rua participasse do estudo, o que resultou em 10 famílias por área, totalizando 30 famílias.

Foi realizada visita domiciliária a cada família sorteada, com objetivo de apresentar a proposta do estudo, convidá-la a participar da sessão de grupo focal e obter assinatura do Termo de Consentimento Livre e Esclarecido (TCLE). Entretanto, somente foi possível contato com 24 famílias. Destas, apenas oito famílias assinaram o TCLE. Assim, participaram do grupo focal um casal, sete mães e uma avó.

Os dados foram coletados por meio de um grupo focal, no qual as falas foram gravadas e transcritas posteriormente. O grupo focal foi subdividido em três momentos: no primeiro, os participantes identificaram individualmente sua rede social de apoio, por meio da seguinte solicitação: coloque seu nome no centro da folha em branco e inclua as pessoas à sua volta que você considera importantes e os serviços ou pessoas da sua comunidade que auxiliam você no cuidado com as crianças.

A realização desta atividade subsidiou o segundo momento, caracterizado pela discussão dos conceitos de rede, apoio e rede social, a partir do conhecimento do grupo, e teorizado pelas concepções ${ }^{(5)}$ sobre o tema.

Optou-se pela utilização do Mapa Mínimo de Relações (MMR), porque sua aplicabilidade é acessível a diferentes culturas, situações econômicas, níveis de instrução, e por considerar o significado individual atribuído aos componentes da rede social de apoio(5). Assim, no terceiro momento, realizou-se a identificação dos membros da rede social de apoio às famílias. Os dados gerados foram agrupados de acordo com o $\mathrm{MMR}^{(5)}$ (Figura 1).

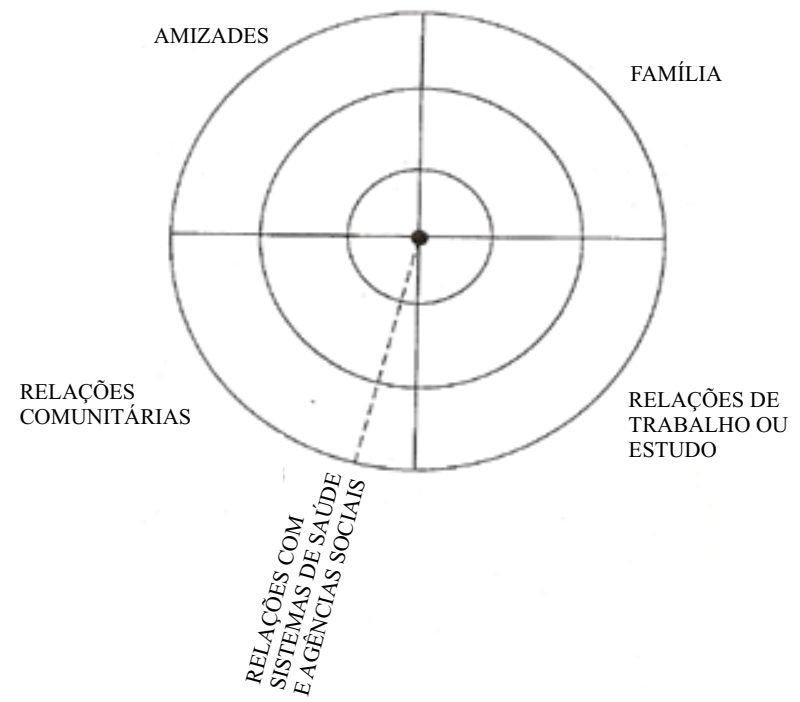

Figura 1 - Mapa Mínimo de Relações proposto por Sluzki( ${ }^{(5)}$
O mapa é composto por quatro quadrantes, que representam as diferentes relações sociais: família, amizades, trabalho ou escolares e relações comunitárias e credo, subdividida em sistemas de saúde e agências sociais. Os quadrantes são subdivididos em três círculos concêntricos que indicam a proximidade das relações. O interno representa as relações íntimas, o intermediário as sociais ou profissionais e o externo os conhecidos e as relações ocasionais $^{(5)}$.

A Figura 1 foi exposta em um cartaz, e as seguintes perguntas foram feitas pelo pesquisador, aos participantes do grupo: quem são as pessoas importantes de sua vida? Quem são as pessoas com quem você pode contar no cuidado com as crianças? Quais os serviços ou lugares da comunidade que Ihe proporcionam algum tipo de auxílio no cuidado com as crianças? Emergiram os membros indicados pelo grupo, que foram inseridos no MMR pelo pesquisador conforme o grau de relacionamento estabelecido entre os membros e as famílias (Figura 2).

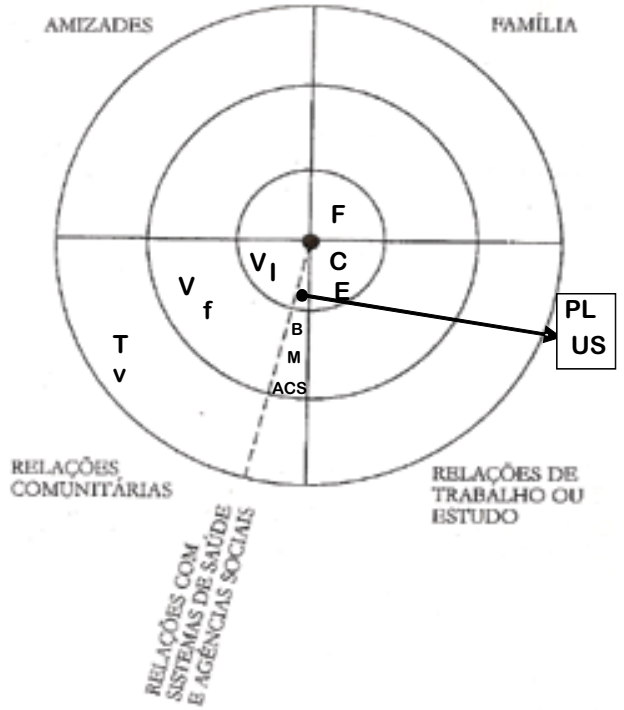

Figura 2 - Rede social de apoio construído pelas famílias baseado na proposta de Sluzki ${ }^{(5)}$

\begin{tabular}{|c|c|c|c|}
\hline \multicolumn{4}{|c|}{ Legenda } \\
\hline ACS & $\begin{array}{l}\text { Agente Comunitário da } \\
\text { Saúde }\end{array}$ & 1 & Igreja \\
\hline B & Bolsa Família & PL & Programa do Leite \\
\hline C & Creche & M & $\begin{array}{l}\text { Médico Clinico Geral, Pediatra, } \\
\text { Dentista }\end{array}$ \\
\hline$E$ & Escola & $\mathrm{T}$ & Programas de televisão e DVD \\
\hline $\mathrm{F}$ & $\begin{array}{l}\text { Família (bisavó, avó, filha, } \\
\text { irmã, mãe) }\end{array}$ & US & Unidade de saúde \\
\hline $\mathrm{F}$ & Farmácia & V & Vizinho \\
\hline
\end{tabular}

A análise dos dados foi realizada por meio da técnica de Análise de Conteúdo(7), por ser um instrumento de análise que facilita a tentativa exploratória e enriquecedora das interpretações.
Mapa da rede social de apoio às famílias para a promoção do desenvolvimento infantil Alexandre AMC, Labronici LM, Maftum MA, Mazza VA 
O projeto de pesquisa foi aprovado pelo Comitê de Ética em Pesquisa da Universidade Federal do Paraná (CAAE: 3145.0.000.091-09) e obteve-se também a concordância da Secretaria Municipal de Saúde do município. Para manter o anonimato dos sujeitos utilizou-se a nomenclatura $F$, seguida de um número sequencial (1 a 8), para nomear cada sujeito.

\section{RESULTADOS}

A partir da análise dos dados acerca da rede social de apoio às famílias, emergiram três categorias: Membros da rede social de apoio das famílias; Mapa da rede social de apoio informal e formal; Recursos utilizados pelas famílias para a promoção do desenvolvimento infantil.

O Quadro 1 apresenta a caracterização dos participantes da pesquisa, sendo que a média de idade foi de 31 anos, a maioria com ensino fundamental incompleto, uma média de 4,75 membros por família e 2,4 filhos com ocupações diversas.

Quadro 1 - Identificação dos membros que representaram as famílias - Colombo, PR - 2009

\begin{tabular}{|ccclccl|}
\hline Famílias & $\begin{array}{c}\text { Identificação } \\
\text { do membro }\end{array}$ & Idade & \multicolumn{1}{c}{ Escolaridade } & $\begin{array}{c}\text { N. }^{\text { }} \text { membros } \\
\text { por família }\end{array}$ & N. ${ }^{\text {filho }}$ & Ocupação \\
\hline F1 & Mãe (F1) & 25 & Ensino Médio & 06 & 02 & Do lar \\
F2 & Mãe (F2) & 28 & Ensino Médio & 03 & 01 & Zeladora \\
F3 & Mãe (F3) & 38 & Ensino fund. Incompleto & 08 & 06 & Doméstica \\
F4 & Avó (F4) & 37 & Ensino fund. Incompleto & 06 & 01 & Do lar \\
F5 & Mãe (F5) & 24 & Ensino fund. Incompleto & 04 & 02 & Do lar \\
F6 & Mãe (F6) & 30 & Ensino superior incompleto & 04 & 02 & Do lar \\
F7 & Mãe (F7) & 20 & Ensino fund. Incompleto & 04 & 02 & Diarista \\
F8 & Mãe e Pai (F8) & 46 & Ensino fund. Incompleto & 03 & 03 & Do lar, eletrotécnico. \\
\hline
\end{tabular}

\section{Membros da rede social de apoio às famílias}

Os participantes indicaram como membros que compunham a rede social de apoio às famílias para a promoção do desenvolvimento infantil: creche, unidade de saúde, irmã materna, bisavó, avó, filhas, mães, farmácia, Programa do Leite, Bolsa Família, amigas, vizinhos, escola, médico clinico geral e pediatra, dentista, igreja, segurança, programas de televisão (TV), DVD (Digital Versatile Dics), (Agentes Comunitários da Saúde (ACS) e Pastoral da Criança, agrupados no $M^{M} R^{(5)}$ (Figura 2).

A rede social de apoio elaborada pelas famílias foi composta com um total de 16 membros. A distribuição destes membros teve maior concentração no círculo interno, conforme apresentado no mapa (Figura2), considerada uma rede localizada.

\section{Mapa da rede social de apoio formal e informal}

No mapeamento da rede social de apoio às famílias, emergiram dois tipos de rede - formais e informais. Os membros da rede social de apoio informal foram representados pelas Relações Familiares (mãe, filhas, avós, bisavós, irmã) e Relações Comunitárias (vizinhos); e da formal, foram elencadas as Relações de Trabalho ou Estudo (creche, escola), Agências Sociais (unidade de saúde, ACS, médico, Programa do Leite, Bolsa Família) e Relações Comunitárias (Igreja, farmácia).

\section{Rede social de apoio informal}

Nesta modalidade, as famílias indicaram como membros da rede social familiar mães, avós, bisavós, filhas e irmãs.

Eu só tenho a irmã, que é o ente mais próximo de mim (F8).

(...) a minha avó sempre ajuda. Porque eu vou fazer algum serviço, trabalhar de doméstica, daí ela sempre fica com eles (F7).

Tem as mães!(...) as bisavós das crianças também ajudam (F5).

Tem a minha filha! (F4).

(...) é minha filha que fica com eles, ajuda a cuidar (F3).

Ainda nessa categoria, as famílias indicaram os vizinhos como membro de composição da rede, porém, não houve um consenso sobre o tipo de relação estabelecida para indicar se eles compõem o círculo interno ou intermediário no MMR como expresso nas falas abaixo:

Os vizinhos (F1).

(...) meu marido chegou e ela [vizinha] falou: olha, ela foi levar a [nome da criança] no médico, porque ela estava com febre e ela não quis esperar tarde da noite. (...) então neste caso, o vizinho também ajuda porque, se eu não falasse com o vizinho, ou não falasse com ninguém, eles iam chegar, e além de não poder entrar em casa, ia pensar o que aconteceu? Onde foi? (F8). 
(...) para mim já é mais distante. [os vizinhos - círculo intermediário ou externo] (F4).

(...) pode ajudar bastante como pode ajudar pouco, em minha opinião é mais ou menos [os vizinhos - círculo intermediário] (F2).

Depende de cada caso. Como a minha família mora longe, então para mim os vizinhos estão mais próximos, porque moram no mesmo quintal, é muito mais fácil falar com os vizinhos quando preciso sair (...) [os vizinhos - círculo interno] (F5).

\section{Rede social de apoio formal}

Emergiram como membros da rede social de apoio formal às famílias a creche e a escola, que foram incluídas no círculo interno do quadrante Relações de trabalho e/ ou Estudo, indicando uma relação muito próxima das famílias, como descrito abaixo:

(...) a creche (F2).

(...) a escola ajuda muito (F3)

(...) eu não uso [a creche], mas tem gente que usa (...) quem precisa da creche, é todos os dias a creche. (F8).

Nesta categoria, as famílias também indicaram, no quadrante das Relações Comunitárias e na subdivisão de Relações com Sistema de Saúde e Agências Sociais, a unidade de saúde, alguns profissionais como médico pediatra, clínico geral, dentista e ACS e serviços de farmácia como membros que compõem a rede de apoio social.

(...) o posto de saúde Clínico Geral. Pois a gente vai ao postinho e é clínico geral. (F2)

Eu me ocupava tanto (...) que eu estava até d-eixando passar a vacina dos nove meses dela, se a ACS não fosse lá, ia passar Farmácia (F8).

(...) médico primeiro e depois vem o pediatra (F1).

(...) ajuda [a família no cuidado à criança], porque muitas vezes, por exemplo, eu, na época não tinha esse negócio, agora que nem ela nasceu e já passou até pelo dentista (F3).

Ao discutir com as famílias o tipo de relação estabelecido com a Unidade de Saúde, ficaram evidenciadas comparações entre a relação com a unidade de saúde e a creche, e a unidade de saúde e a família, conforme falas abaixo:

(...) a creche ainda continua em primeiro [comparado com a unidade de saúde] (F1).

(...) o posto é o mesmo da creche, para quem precisa, é todos os dias, posto quando precisa que vai lá, mas quem precisa da creche, são todos os dias (...) Eu acho que quando a gente tem algum problema, a gente procura a família depois o posto, que o apoio mais próximo é a família e depois o posto (F8)
(...) no ponto de vista de ser todos os dias, (...) quem necessita da creche todos os dias então, a creche está em prioridade [que a unidade de saúde] (F4).

(...) do ponto de vista de necessidade, ele ficaria em segundo plano [a unidade de saúde em relação a creche] (F3).

(...) antes de procurar a família, em primeiro lugar é o posto de saúde (F2).

Foram mencionadas também as políticas sociais de apoio às famílias, representadas pelos Programa do Leite e Bolsa Família, como apresentado nas falas a seguir:

O programa do leite é bem importante (...) usa bastante porque a gente pega leite na segunda, na quarta, na sexta, e sempre (F7).

O bolsa família, ajuda muito. Mais longe, que não é a todo mundo que ajuda [círculo externo - bolsa família] (F5).

Para quem usa o Bolsa Família, que isso é uma ajuda pra criar as crianças (F8).

As famílias evidenciam diferentes relações entre o Programa do leite e o Bolsa família, pois foram incluídos no círculo interno e intermediário, respectivamente, no quadrante das Relações com sistema de saúde e agências sociais (Figura 2).

Outro membro referido na rede social formal foi a Igreja, como apoio espiritual, e que contribui com a família na educação das crianças.

(...) a igreja ajuda a ter mais (...), a ser mais católico, não falar palavrão, não xingar (...) ajuda as crianças a não ser briguento, a não xingar as pessoas (F3).

(...) a igreja ajuda bastante na educação (...) (F6).

\section{Recursos utilizados pelas famílias para a promoção do desenvolvimento infantil}

Os programas de televisão e o DVD foram indicados pelas famílias como recursos que as auxiliam no cuidado com as crianças. Todavia, estes recursos tecnológicos são apontados por algumas famílias como benéficos, e, por outras, como prejudiciais ao desenvolvimento infantil conforme mencionado nos fragmentos das falas:

(...) a televisão (...) tem programas educativos para as crianças e para os pais (...) você não coloca um DVD para as crianças assistirem? Não vê um programa educativo que você fica mais informado disso, que você tira suas dúvidas? (F6).

(...) tem programas e desenhos que não tem problema a gente deixar assistir (F4).

(...) o jornal também que passa na TV (F3).

Nem todos [os programas], por exemplo, eu não vou colocar minha filha assistir todos os programas, mas tem 
aqueles que são educativos, que a gente os deixa assistirem, cmpra um DVD lá para eles (F3).

(...) ensina educar eles melhor, o modo de não ficar gritando, não ter violência assim com eles, ter mais calma pra cuidar [citando um programa] (F7).

Mesmo após uma intensa exposição de ideias, as famílias não chegaram a um consenso, e os programas de TV e o DVD foram indicados como membros da rede social de apoio às famílias, incluídos no círculo externo do quadrante Relações Comunitária (Figura 2) em uma situação de ocasionalidade.

\section{DISCUSSÃO}

A composição da rede social de apoio às famílias, por 16 membros, concentrados no círculo interno, é considerado menos flexível e efetivo, pois gera menos opções de integração e apoio entre os membros do que as redes de distribuição mais ampla(5). As condições de sobrecarga e trabalho estão correlacionadas com o tamanho da rede, indicada por meio do número de membros que a compõem ${ }^{(5)}$. Assim, as redes de tamanho médio caracterizam-se pela sua maior flexibilidade e efetividade do que as redes de tamanho pequeno ou grande. As redes mínimas são menos efetivas em situações de tensão e sobrecarga de longa duração, devido ao distanciamento que os membros estabelecem entre si para evitar esta sobrecarga. Já a redes numerosas apontam o risco desta inefetividade fundamentada na suposição de que alguém já deve estar cuidando do problema ${ }^{(5)}$.

No que se refere às funções desempenhadas pelos membros da rede, tem-se que em cada vínculo estabelecido podem ser desempenhadas uma ou várias funções, todavia,

as relações íntimas familiares e de amizade costumam abarcar simultaneamente um número importante de funções, muitas das quais, por sua riqueza, complexidade ou idiossincrasia, transcendem as especificidades dessa listagem $^{(5)}$.

Contudo, não se podem estabelecer funções específicas para cada um dos membros citados.

No mapeamento da rede social de apoio às famílias, emergiram dois tipos de rede - formais e informais. Entende-se por rede social formal aquela na qual a composição se relaciona à posição e aos papéis desempenhados por seus membros na sociedade, incluindo profissionais de saúde, entre outros; e rede social informal é aquela na qual os membros têm relevância pelas relações na dimensão pessoal e afetiva, entre eles família, amigos, vizinhos em meio a outros ${ }^{(8)}$.

Na rede social de apoio informal, a presença de membros da família ampliada corroboram a literatura ao afirmar que a família ampliada compõe a rede social de apoio familiar no cuidado às crianças, e os avós em especial têm participação relevante na promoção do desenvolvimento infantil (...) $)^{(9)}$. Para os grupos populares, o conceito de família ancora-se nas atividades diárias e nas redes de ajuda mútua ${ }^{(10)}$, ou redes de solidariedade, muitas vezes eficazes nos cuidados necessários a seus membros ${ }^{(11)}$.

A contribuição dos membros do gênero feminino ligados à consanguinidade da mãe evidencia as influências culturais e hierárquicas, em que o cuidado às crianças é atribuído à mãe e à sua rede de sociabilidade, por meio da confiança depositada em outras mulheres ${ }^{(12)}$.

A indicação dos vizinhos como membro da rede social de apoio às famílias, também foi evidenciado em outros estudos $^{(2-3)}$ sendo indicados como membros importantes diante das modificações internas que ocorrem nas famílias, como, por exemplo, nascimento de filhos, casamentos, mortes, entre outras.

Enfatiza-se nestas relações a migração ou mudança de área geográfica cada vez mais comum na sociedade. Nesta transição, as necessidades dos indivíduos aumentam, e sua rede social de apoio se rompe. O esforço para desenvolver novas redes, associado às características do novo lugar, é que determinam a ambientação do sujeito e o estabelecimento de uma nova rede social de apoio(5), acarretando possibilidades de auxílio às famílias na promoção do desenvolvimento infantil.

Na rede social de apoio formal, a referência da creche e da escola no círculo interno do quadrante Relações de Trabalho e/ou estudo expressam a relevância destas no apoio às famílias, independentemente de ser utilizada ou não. Relatam esta importância pelo grau de regularidade no uso deste apoio, corroborando o conceito de rede caracterizada pela soma de todas as relações que um indivíduo percebe como significativa (... $)^{(5)}$. Reforça-se aqui o papel destas instituições em relação às experiências que proporcionam às crianças no estabelecimento de relações de confiança em si e na sociedade ${ }^{(13)}$.

Caracterizou-se a presença de diferentes profissionais de saúde por meio da participação destes na equipe multiprofissional, em atividades e ações como prevenção de doenças e promoção da saúde. O reconhecimento destes pelas famílias pode favorecer o estabelecimento de relações mais confiáveis entre profissional-usuário(14), e pode gerar interações favoráveis entre os membros da rede social de apoio às famílias, de modo a contribuir para a promoção do desenvolvimento infantil.

A discussão referente a relação estabelecida entre unidade de saúde e a creche, e a unidade de saúde e a família, exemplificou as diferenças de interesse quanto à utilização destes serviços, fundamentadas nas distintas relações sociais, renda, escolaridade, trabalhos formais e informais, entre outros. Este dissenso reforça a dimensão singular na significação da rede social de apoio às famílias e indica os principais membros da rede social de apoio procurados pelas famílias, para a resolução de agravos à saúde. 
A menção de programas governamentais como membros da rede social de apoio às famílias, também foi evidenciado em estudo semelhante, referido como uma ação que contribui com as famílias, porém, com ressalvas diante da dificuldade de acesso ${ }^{(9)}$.

A Igreja, membro referido pelas famílias como integrante da rede social de apoio, também foi identificada em um estudo realizado com enfermeiros da rede de atenção básica, sendo esta identificada como fornecedora de apoio espiritual ${ }^{(6)}$, corroborando os achados desta pesquisa.

De acordo com outro estudo(15), as pessoas têm buscado espaços alternativos para enfrentar problemas relacionados à saúde, demonstrando a relevância que as famílias depositam no papel da religião como complemento dos serviços médicos estruturados.

A referência aos programas de televisão e DVD, corroboram com um estudo(9), que expressou não haver consenso das famílias sobre a utilização destes recursos, mostrando também que só contribuem se houver um acompanhamento da qualidade dos programas utilizados.

A relação das famílias com os membros da sua rede social de apoio, entre eles familiares, instituições não governamentais, projetos comunitários e instituições religiosas é apontado por um estudo ${ }^{(16)}$, como potencial para a promoção da vida saudável, evidenciado por meio da importância das organizações e recursos disponíveis, além da necessidade de fortalecer a importância de mais recursos e das políticas publicas sociais.

Deve-se considerar que a rede social não é estática, sofre mudanças constantes, sendo comandada por mecanismos automáticos desenvolvidos pelo grupo que a compõe. Neste sentido, observou-se, nas discussões, dissonância entre os integrantes do grupo referente à inclusão de alguns indivíduos e serviços na rede social de apoio às famílias, principalmente ligada ao tipo das relações estabelecidas.

\section{REFERÊNCIAS}

1. Fundo das Nações Unidas para a Infância (UNICEF). Situação Mundial da Infância, 2008. Caderno Brasil [Internet]. Brasília; 2008 [citado 2010 abr. 22]. Disponível em: http://www.unicef.org/brazil/pt/cadernobrasil2008.pdf

2. Serapioni M. O papel da família e das redes primárias na reestruturação das políticas sociais. Ciênc Saúde Coletiva. 2005;10 Supl:243-53.
A familiaridade com o tema desenvolvido pelos participantes na construção da rede social de apoio coloca-os em uma posição favorável, conduzindo-os a mudanças de planos viáveis ${ }^{(5)}$, além de gerar uma experiência para que se tornem agentes ativos de sua própria transformação, buscando alternativas e meios para melhoria da qualidade de vida da criança e da família, além da promoção do desenvolvimento infantil.

\section{CONCLUSÃO}

A possibilidade de identificar a rede social de apoio às famílias para a promoção do desenvolvimento infantil permite aos profissionais da saúde melhor compressão do potencial dela com relação à saúde, tanto no atendimento individual quanto coletivo. Portanto, é indispensável considerá-la significativa para os indivíduos, pois é nela que os profissionais podem identificar e discutir maneiras de potencializa ações para incentivar o desenvolvimento infantil e até de cuidados essenciais à criança.

É preciso que os profissionais da saúde estabeleçam uma relação mais próxima com os usuários, a fim de que as atividades desenvolvidas de educação em saúde sejam reconhecidas e usufruídas pelas famílias para a melhoria da qualidade de vidas das crianças.

Os profissionais podem e devem desenvolver estratégias de ligação entre os membros da rede social de apoio disponível às famílias, visando à promoção do desenvolvimento, além de encorajá-las a serem agentes ativos e buscarem coletivamente recursos e serviços da comunidade que propiciem melhorias na qualidade de vida.

Considera-se relevante a realização da pesquisa em outros locais, a fim de confirmar e validar a rede social de apoio às famílias, por meio da qual os profissionais podem propor projetos de intervenção, com o intuito de melhorar a qualidade de vida das crianças.
3. Ribeiro KSQS. Redes sociais e educação popular: aproximação teórica e mudanças na prática de educação popular em saúde. In: Anais do V Colóquio Internacional Paulo Freire; 2005 set. 19-22; Recife, PE, Brasil [Internet]. 2005 [citado 2010 abr. 15]. Disponível em: http://www.paulofreire.org.br/pdf/comunicacoes_orais/REDES\%20SOCIAIS\%20E\%20EDUCAÇÃO\% 20POPULAR-\%20APROXIMAÇÃO\%20TEÓRICA\%20E\%20MUDANÇAS\%20NA\%20PRÁTICA\%20DE\%20EDUCAÇÃO\%20POPULAR\%20EM\%20SAÚDE.pdf 
4. Brasil. Ministério da Saúde; Secretaria de Atenção à Saúde; Departamento de Atenção Básica. Política Nacional de Atenção Básica [Internet]. Brasília; 2006 [citado 2010 ago. 22]. Disponível em: http://portal.saude.gov.br/portal/arquivos/pdf/ politica_nacional_atencao_basica_2006.pdf

5. Sluzki CE. A rede social na prática sistêmica: alternativas terapêuticas. São Paulo: Casa do Psicólogo; 1997.

6. Marcon SS, Zani AV, Waidman MAP, Radovanovic CAT, Decesaro MN, Carreira L. Rede social e família: o olhar sensível dos enfermeiros construtores da prática. Ciênc Cuidado Saúde. 2009;8 Supl:31-9.

7. Bardin L. Análise de conteúdo. Lisboa: Edições 70; 2004.

8. Bocci SCM, Ângelo M. Entre a liberdade e a reclusão: o apoio social como componente da qualidade de vida do binômio cuidador familiar-pessoa dependente. Rev Lat Am Enferm. 2008;16(1):15-23.

9. Mazza VA. Necessidades das famílias com relação ao desenvolvimento infantil à luz da promoção da saúde [tese doutorado]. São Paulo: Escola de Enfermagem, Universidade de São Paulo; 2007.

10. Fonseca C. Concepções de família e práticas de intervenção: uma contribuição antropológica. Saúde Soc [Internet]. 2005 [citado 2010 fev. 20];14(2):50-9. Disponível em: http:// www.scielo.br/pdf/sausoc/v14n2/06.pdf
11. Solymos GMB, Soares MLV. A família e o seu contexto. In: 1a Oficina Nossas Crianças: Janelas de Oportunidades. São Paulo: Secretaria Municipal de Saúde, Programa Saúde da Família; 2002. p. 25-36.

12. Sarti CA. A família como espelho: um estudo sobre a moral dos pobres. 4a ed. São Paulo: Cortez; 2007.

13. Chiesa AM, Veríssimo MDLOR, Fracolli LA. O Projeto Nossas Crianças: Janelas de Oportunidade: possibilidades e limites para a atenção à criança. In: Chiesa AM, Zoboli E, Fracolli LA. Promoção da Saúde da Criança: a experiência do Projeto Nossas Crianças: Janelas de Oportunidades. São Paulo; 2009.

14. Veríssimo MLOR. O desenvolvimento infantil e o cuidado da criança pela família. In: 1a Oficina Nossas Crianças: Janelas de Oportunidades. São Paulo: Secretaria Municipal de Saúde, Programa Saúde da Família; 2002. p. 31-6.

15. Pietrukowics MCLC. Apoio social e religião: uma forma de enfrentamento dos problemas de saúde [Internet]. Rio de Janeiro: FIOCRUZ; 2001 [citado 2010 jan. 25]. Disponível em: http://portalteses.icict.fiocruz.br/pdf/FIOCRUZ/2001/ pietrukmcm/capa.pdf

16. Grippo MLV, Silva FLA. Avaliação de uma cartilha educativa de promoção ao cuidado da criança a partir da percepção da família sobre temas de saúde e cidadania. Rev Esc Enferm USP. 2008;42(3):430-6. 